\section{Sebaceous glands in the esophagus}

A 44-year-old woman with a 2-year history of gastroesophageal reflux was referred to our endoscopy unit for investigation. She was taking over-the-counter ranitidine to treat her symptoms. On examination, the patient was overweight. Her past medical history revealed only borderline hypertension. She did not have dysplipidemia, she did not smoke, and she consumed alcohol only occasionally. Endoscopy showed yellow plaques in the esophagus, interpreted as possible Candi$d a$ infection, and multiple cystic polyps in the gastric fundus, but the single esophageal biopsy that was taken reported only mild inflammation. A repeat endoscopy once again showed numerous yellowish papules in the esophagus ( $\bullet$ Fig. $\mathbf{1}$ ) and multiple biopsies were obtained at this examination.

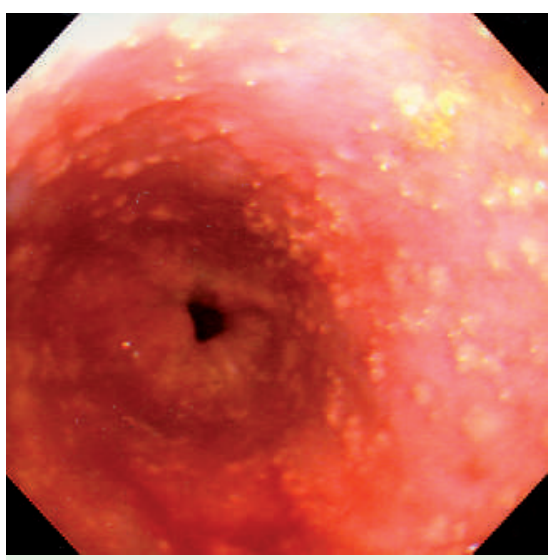

Histological examination revealed strips of esophageal squamous epithelium with heterotopic mature sebaceous glands deep to the esophageal squamous epithelium, associated with mild inflammatory cell infiltration ( $\bullet$ Fig. 2). No fungi were seen. At 1 year the patient is well and her symptoms are controlled on a protonpump inhibitor.

Sebaceous glands are generally confined to the skin, in association with hair follicles from the pilosebaceous apparatus, but can be found independently in other organs, where they are known as "ectopic" (or "heterotopic") sebaceous glands The best-known examples are those occurring in the lips and buccal mucosa (referred to as "Fordyce's spots") [1]. Sebaceous glands have also been detected in other tissues of ectodermal origin [2].

Their presence in the esophagus, an organ of endodermal origin, is a very rare anomaly, and has been reported only rarely in the literature. They therefore present a diagnostic challenge at endoscopy. Both a congenital and a metaplastic origin have been suggested, but it seems more likely that they originate as a result of an acquired metaplastic process [3]. The evidence so far suggests that they are entirely benign in nature and there are no data that suggest a need for further surveillance endoscopies.

Endoscopy_UCTN_Code_CCL_1AB_2AC_3AH
U. Thalheimer ${ }^{1}$, J. L. Wright ${ }^{1}$,

P. Maxwell ${ }^{1}$, J. Firth ${ }^{2}$, A. Millar ${ }^{1}$

${ }^{1}$ Department of Gastroenterology, North Middlesex University Hospital, London, United Kingdom

2 Department of Cellular Pathology, North Middlesex University Hospital, London, United Kingdom

\section{References}

1 Fordyce J. A peculiar affection of the mucous membrane of the lip and the oral cavity. J Cutn Genito-Urin Dis 1896; 14: 413-419

2 Guiducci A, Hyman A. Ectopic sebaceous glands: a review of the literature regarding their occurrence, histology and embryonic relationship. Dermatologica 1962; 125 : 44-63

3 Nakanishi Y, Ochiai A, Shimoda T et al. Heterotopic sebaceous glands in the esophagus: histopathological and immunohistochemical study of a resected esophagus. Pathol Int 1999; 49: 364-368

Bibliography

DOI 10.1055/s-2007-967059

Endoscopy 2008; 40: E57

(c) Georg Thieme Verlag KG Stuttgart - New York . ISSN 0013-726X

\section{Corresponding author}

\section{U. Thalheimer, MD}

Department of Gastroenterology

North Middlesex University Hospital

Sterling Way

London N18 1QX

United Kingdom

Fax: +39-045-8202222

uthalheimer@gmx.net
Fig. 1 An upper gastrointestinal endoscopic image showing multiple small sebaceous glands.

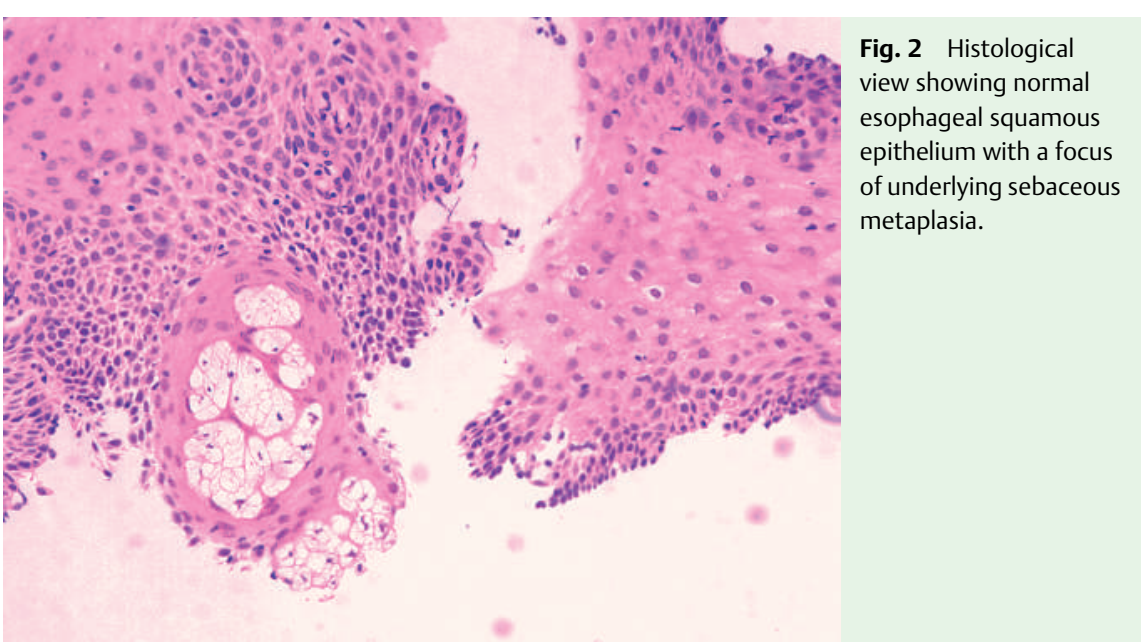

